\title{
IMPLEMENTASI PENGUKURAN KINERJA MODEL MALCOLM BALDRIGE UNTUK KINERJA UNGGUL DALAM MENINGKATKAN KEUNGGULAN BERSAING DI PT POS INDONESIA
}

\author{
Hesti Sugesti $^{1}$, Angga Dewi Anggraeni ${ }^{2}$ \\ ${ }^{1,2}$ Program Studi D-IV Manajemen Perusahaan, Politeknik Pos Indonesia \\ E-mail : hestisugesti@poltekpos.ac.id ; anggadewi@poltekpos.ac.id
}

Diterima: 1 Februari 2020; Direvisi: 9 Maret 2020; dipublikasikan: 30 April 2020

\begin{abstract}
Problems faced by PT. Pos Indonesia is the number of private competitors engaged in logistics, making it difficult to compete in the industry. By implementing company performance measurement using the Malcolm Balridge Performance Excellence model, it is expected that PT. Pos Indonesia can find out its advantages and can improve it. Based on the results of research to 88 respondents using quantitative verification methods, obtained an overview of the company's performance is in the very good category but the measurement of company performance has not been fully measured using the Malcolm Balridge method, and a picture of competitive advantage in either category. From the data analysis test results obtained by the company's performance with the Malcolm Balridge model has a positive and significant effect on competitive advantage at PT. Pos Indonesia.
\end{abstract}

Keywords: MBCfPE, Competitive Advantage, Performance Excellence.

\begin{abstract}
ABSTRAK
Permasalahan yang dihadapi PT. Pos Indonesia adalah jumlah kompetitor swasta yang terlibat dalam bidang logistik sehingga sulit berkompetisi di industri ini. Dengan menerapkan pengukuran kinerja perusahaan dengan menggunakan model Malcolm Balridge Performance Excellence, diharapkan PT. Pos Indonesia dapat mengetahui keuntungannya dan dapat meningkatkannya. Berdasarkan hasil penelitian terhadap 88 responden dengan menggunakan metode verifikasi kuantitatif, diperoleh gambaran kinerja perusahaan dalam kategori yang sangat baik tetapi pengukuran kinerja perusahaan belum sepenuhnya diukur dengan menggunakan Malcolm Metode balridge, dan gambar keunggulan kompetitif dalam kategori baik. Dari hasil uji analisis data yang diperoleh kinerja perusahaan dengan model Malcolm Balridge memiliki efek positif dan signifikan terhadap keunggulan kompetitif di PT. Pos Indonesia.
\end{abstract}

Kata Kunci: MBCfPE, Keunggulan Kompetitif, Kinerja Unggul. 


\section{PENDAHULUAN}

Pada saat ini, proses pengiriman barang sangat sering dilakukan oleh masyarakat luas dan prosesnya pun berlangsung sangat cepat. Tingginya frekuensi pengiriman barang tersebut salah satunya disebabkan oleh maraknya penjualan online dan pengiriman dokumen-dokumen yang dilakukan oleh perusahaan. Hal inilah yang membuat pasar jasa pengiriman barang semakin tumbuh berkembang. Kemajuan ekonomi global dan teknologi yang cepat menimbulkan persaingan usaha yang sangat ketat di berbagai sektor. Persaingan antar perusahaan jasa salah satunya karena banyaknya pesaing baru yang berdatangan, bahkan perusahaan dari luar negeri pun ikut memasuki pasar jasa pengiriman barang di Indonesia. Perkembangan perusahaan yang semakin pesat menimbulkan persaingan yang semakin tinggi sehingga perusahaan membutuhkan strategi untuk mempertahankan keberadaannya untuk jangka waktu yang panjang. Pengelolaan manajemen strategis merupakan proses penting bagi entitas bisnis. Sebuah perusahaan yang dikategorikan sukses apabila bisa memenangkan persaingan.

Salah satu Badan Usaha Milik Negara (BUMN) yang bergerak dalam bidang jasa pelayanan lalu lintas berita, uang, barang dengan memiliki jaringan pelayanan terbesar dan tersebar di seluruh pelosok tanah air adalah PT Pos Indonesia. PT Pos Indonesia dituntut dapat memiliki nilai lebih di mata masyarakat dan tidak kehilangan pelanggan setianya dalam persaingannya. Kondisi tersebut menuntut suatu perusahaan untuk selalu mengembangkan strategi perusahaan agar dapat bertahan, berdaya saing dan terus berkembang di tengah gencarnya persaingan usaha, oleh sebab itu perusahaan perlu mengembangkan suatu strategi yang tepat agar perusahaan dapat mempertahankan eksistensinya dan dapat memperbaiki kinerja perusahaan.

Adapun analisis SWOT dari PT Pos Indonesia adalah sebagai berikut:

Tabel 1 Analisis SWOT PT Pos Indonesia

\section{Strength}

PT. Pos Indonesia berkomitmen untuk memberikan solusi terhadap permasalahan fungsi logistik pelanggan, dengan kerangka kerjayang bersinergi dan bekerjasama untuk mencapaitujuan.

PT. Pos Indonesia terfokus pada penciptaan nilai tambah bagipelanggan melalui penurunan harga, peningkatan layanan, implementasi yang lebih cepat dan fleksibel.

\section{Weakness}

Kurangnya iklan publikasi untuk informasi produk,

Produk - produk inovasi baru PT POS INDONESIA masih digunakan oleh masyarakat menengah ke atas contohnya seperti mail online

\section{Opportunity}

Jasa antaran lebih cepat dan terpercaya di dalam negeri atau secara terbatas ke luar negeri melalui kerja sama dengan pemainpemain besar, seperti yang dilakukan U.S. Postal Service dengan DHL dan FedEx.

\section{Threat}

Teknologi informasi juga kerap membawa instabilitas terhadap bisnis satu perusahaan.

Sumber: (www.posindonesia.co.id. 2018) 
Volume 12, No. 1, April 2020, pp. 1-9

e-ISSN: 2502-5449

p-ISSN: 2085-2266

DOI : $10.30998 /$ sosioekons.v12i1.5672

Sementara penghargaan yang diraih PT Pos Indonesia adalah sebagai berikut:

Tabel 2 Penghargaan yang diraih PT. Pos Indonesia

\begin{tabular}{lc}
\hline \multicolumn{1}{c}{ Nama Penghargaan } & Tahun \\
\hline Digital Innovation Award 2018 & 2018 \\
\hline Indonesia Netizen Brand Choice Award 2018 & 2018 \\
\hline Contact Center Service Excellence Award 2018 & 2018 \\
\hline Indonesia Domestic Express Service Provider of The Year 2017 & 2017 \\
\hline Superbrands 2015 & 2015 \\
\hline Sumber: (“www.posindonesia.co.id," 2018)
\end{tabular}

Berdasarkan tabel di atas, dapat dilihat analisis SWOT pada PT Pos Indonesia dan beberapa penghargaan yang diraih sebagai bentuk keunggulan bersaing. Keunggulan bersaing adalah keadaan di mana perusahaan dapat menciptakan posisi pertahanan yang baik atas pesaing-pesaingnya. Keunggulan bersaing didasarkan pada kompetensi khusus, yaitu kekuatan spesifik perusahaan yang dapat menjadikan perusahaan mampu membuat produknya berbeda dengan produk yang ditawarkan pesaing dan mempunyai harga yang lebih rendah dibandingkan pesaing.

Namun bagi masyarakat, PT Tiki JNE lebih dikenal dibandingkan PT Pos Indonesia, terlebih pada pelanggan setia online shop seperti Lazada, Zalora, Salestock, Shopee dan lainnya. Website belanja online di Indonesia mayoritas menggunakan jasa kurir PT Tiki JNE dalam mengirimkan produk yang dijual kepada konsumennya dibandingkan PT Pos Indonesia. (Katadata, 2018)

Sama seperti PT Pos Indonesia, JNE meraih beberapa penghargaan yang di antaranya adalah Top Brand Award. Top Brand Award didasarkan atas hasil riset terhadap konsumen Indonesia. Pemilihan merek terbaik berdasarkan atas pilihan konsumen, maka tidak salah jika konsumen lebih sering menggunakan jasa pengiriman JNE. Fenomena ini membuat nama PT Pos Indonesia kurang dikenal dan diminati sebagai jasa pengiriman barang.

Keunggulan bersaing yang dimiliki oleh PT Pos Indonesia diharapkan akan mampu menjadikan kinerja perusahaan menjadi baik. Salah satu cara untuk mengukur peningkatan kinerja yaitu menggunakan model Malcolm Baldrige Criteria for Performance Excellence. Menurut Gasperzs (Utami, P. Setyorini, 2014), Malcolm Baldrige Criteria for Performance Excellence (MBCfPE) merupakan salah satu metode peningkatan kinerja organisasi secara keseluruhan dan terus-menerus dengan menggunakan pengukuran dan memberikan feedback mengenai kinerja organisasi secara keseluruhan dalam penyediaan produk dan jasa yang berkualitas. National Institute Standard of Technology dalam Utami (2014), dasar MBCfPE terdiri dari 7 kriteria yang terintegrasi yang disebut critera for performance excellence yaitu leadership, strategic planning, customer and market fokus, measurement analysis and knowledge management, human resource fokus, process management serta business result.

Dengan mengaplikasikan model pengukuran Malcolm Baldrige for Perfomance Excellence yang berstandar internasional, diharapkan pula dapat membantu perusahaan dalam mengukur kinerja perusahaannya, mulai dari level pimpinan hingga level karyawan dan pelanggannya. Pada akhirnya nanti akan diketahui dan disimpulkan bagaimana kualitas dan nilai kinerja perusahaan sesuai kriteria-kriteria yang ada di model pengukuran Malcolm Baldrige ini. Melalui pengukuran kinerja ini juga akan didapatkan solusi perbaikan yang bisa dilakukan oleh perusahaan yang salah satunya tidak terlepas dari faktor kepemimpinan yang merupakan kekuatan pendorong bagi sistem di perusahaan yang menciptakan hasil.

Adapun tujuan penelitian yang ingin dicapai dalam penelitian ini adalah untuk mengetahui bagaimana gambaran kinerja perusahaan dengan MBCfPE di PT Pos Indonesia, 
untuk mengetahui gambaran keunggulan bersaing di PT Pos Indonesia serta pengaruh kinerja perusahaan dengan MBCfPE terhadap keunggulan bersaing di PT Pos Indonesia.

\section{METODE}

Metode penelitian adalah metode yang digunakan untuk menghitung data yang diamati oleh manusia. Metode yang digunakan dalam penelitian ini adalah metode kuantitatif. Menurut (Sugiyono, 2017) metode kuantitatif adalah metode penelitian yang bekerja dengan angka, yang datanya berwujud bilangan (skor atau nilai, peringkat, atau frekuensi), yang dianalisis dengan menggunakan statistik untuk menjawab pernyataan atau hipotesis penelitian yang sifatnya spesifik, dan untuk melakukan prediksi bahwa suatu variabel tertentu mempengaruhi variabel yang lain.

Sementara populasi dalam penelitian ini adalah seluruh manager di Kantor Pusat PT Pos Indonesia yang menyebar di 3 kantor Pos di Indonesia yaitu : PT Pos Cilaki, PT Pos Banda dan PT Pos Jalan Jakarta yang berjumlah 88 orang. Pada penelitian ini, seluruh populasi dijadikan reponden penelitian sehingga penelitian ini merupakan penelitian populasi.

Jenis data yang digunakan dalam penelitian ini ada dua macam data yaitu:

\section{Data Primer}

Data primer adalah sumber data yang langsung memberikan data kepada pengumpul data. Sumber data primer pada penelitian ini diperoleh dengan melakukan pengamatan langsung atau observasi serta menyebarkan kuesioner.

Observasi dilakukan dengan mengamati kegiatan perusahaan yang berhubungan dengan variabel penelitian. Hasil dari observasi dapat dijadikan data pendukung dalam menganalisis dan mengambil kesimpulan. Sementara kuesioner disebarkan kepada sejumlah responden. Melalui berbagai pernyataan yang diajukan kepada responden maka akan ditentukan skor dari setiap jawaban sehingga menjadi data kuantitatif. Adapun skala yang peneliti gunakan untuk menentukan skor yaitu skala Likert.

\section{Data Sekunder}

Data sekunder adalah sumber data yang diperoleh dari sumber tertulis seperti kajian ilmiah, literature, dan lain sebagainya. Data sekunder dari penelitian ini diperoleh dari studi kepustakaan yaitu dengan cara membaca literature, buku-buku dan semua yang berhubungan dengan penelitian.

Metode analisis data yang digunakan adalah uji validitas dan uji reliabilitas. Validitas merupakan derajat ketepatan antara data yang sesungguhnya terjadi pada obyek penelitian dengan data yang dapat dilaporkan oleh peneliti. (Sugiyono, 2017) berpendapat bahwa "Suatu konstruk atau variabel dikatakan valid jika memberikan nilai Cronbach Alpha > 0,30 ”. Dalam penelitain ini peneliti menggunakan bantuan aplikasi SPSS untuk melakukan uji validitas.

Uji reliabilitas digunakan untuk mencari reliabilitas instrumen dengan rentang skor antara 1-5 menggunakan uji Cronbach's. Pengukuran reliabilitas pada penelitian ini dilakukan dengan membagikan kuesioner pada responden kemudian hasil skornya diukur korelasinya antar skor jawaban pada butir pertanyaan yang sama dengan bantuan SPSS menggunakan uji Cronbach Alpha $(\alpha)$. Suatu konstruk atau variabel dikatakan reliabel jika memberikan nilai Cronbach Alpha $>0,60$.

Sementara teknik analisis data yang digunakan adalah analisis statistik deskriptif dan analisis regresi linear sederhana. (Sugiyono, 2017) berpendapat bahwa analisis deskriptif adalah analisis yang digunakan untuk menganalisa data dengan cara mendeskripsikan atau menggambarkan data yang telah terkumpul sebagaimana adanya tanpa bermaksud membuat 
kesimpulan yang berlaku untuk umum atau generalisasi. Untuk menjawab deskripsi tentang masing-masing variabel penelitian ini, digunakan rentang kriteria penilaian dengan skor.

Skor aktual adalah jawaban seluruh responden atau kuesioner yang telah diajukan. Skor ideal adalah skor atau bobot tertinggi atau semua responden diasumsikan memilih jawaban dengan skor tertinggi. Selanjutnya hasil perhitungan perbandingan antara skor aktual dengan skor ideal dikonrtribusikan dengan tabel sebagai berikut:

Tabel 3. Kriteria Persentase Tanggapan Responden

\begin{tabular}{cc}
\hline Persentase & Kategori Persentase \\
\hline $20 \%-36 \%$ & Tidak Baik \\
\hline $36 \%-52 \%$ & Kurang Baik \\
\hline $52 \%-68 \%$ & Cukup \\
\hline $68 \%-84 \%$ & Baik \\
\hline $84 \%-100 \%$ & Sangat Baik \\
\hline
\end{tabular}

Sumber: Hasil Olahan Penulis, 2018

Regresi sederhana didasarkan pada hubungan fungsional ataupun kausal satu variabel independen dengan satu variabel dependen (Sugiyono, 2017). Model dari regresi linear sederhana yaitu $\mathrm{Y}=\mathrm{a}+\mathrm{bX}$.

Dalam penelitian ini pegujian hipotesis dilakukan hanya dengan menggunakan uji $\mathrm{F}$ (simultan). Uji $\mathrm{F}$ digunakan untuk mengetahui tingkat signifikansi pengaruh variabel independen secara bersama-sama (simultan) terhadap variabel dependen. Hipotesis yang digunakan dalam pengujian ini adalah :

$\mathrm{H}_{1}=$ Terdapat pengaruh MPCfPE terhadap keunggulan bersaing secara positif dan signifikan

$\mathrm{H}_{0}=$ Tidak terdapat pengaruh MPCfPE terhadap keunggulan bersaing secara positif dan signifikan

Koefisien determinasi juga dilakukan untuk mengetahui kesesuaian atau ketepatan antara nilai dugaan atau garis regresi dengan data sampel. Apabila nilai koefisien korelasi sudah diketahui, maka untuk mendapatkan koefisien determinasi dapat diperoleh dengan mengkuadratkannya.

Interpretasi terhadap hubungan korelasi atau seberapa besarnya pengaruh variabelvariabel tidak bebas, digunakan pedoman yang dikemukakan (Sugiyono, 2017) seperti tertera pada tabel berikut:

Tabel 4 Interpretasi Nilai Koefisien Korelasi

\begin{tabular}{cc}
\hline Interval Koefisien & Tingkat hubungan \\
\hline $0,000-0,199$ & Sangat Rendah \\
$0,200-0,399$ & Rendah \\
$0,400-0,599$ & Sedang \\
$0,600-0,799$ & Kuat \\
$0,800-0,999$ & Sangat Kuat \\
\hline
\end{tabular}

Sumber: (Sugiyono, 2017)

\section{HASIL DAN PEMBAHASAN}

Nilai butir item pernyataan yang diuji dengan uji validitas memiliki nilai lebih besar dari $\mathrm{r}_{\text {tabel }}$ sehingga dapat disimpulkan bahwa semua item pernyataan kuesioner kinerja Malcolm Baldrige tersebut dinyatakan valid. Adapun nilai tersebut dapat dilihat pada tabel berikut: 
Nilai butir item pernyataan yang sedang diuji lebih besar dari $r_{\text {tabel }}$ yaitu 0.576 maka dapat disimpulkan bahwa item pernyataan tersebut dinyatakan valid. Hasil uji validitas penyebaran kuesioner variabel Keunggulan Bersaing (Y) yang berjumlah 3 dinyatakan semua valid. Uji yang selanjutnya yang dilakukan yaitu uji reliabilitas. Ketentuan yang menyatakan bahwa sebuah instrumen dikatakan reliabel yaitu apabila nilai Cronbach Alpha memiliki nilai lebih besar dari 0.600. Berdasarkan hasil uji reliabilitas, dapat dinyatakan bahwa kuesioner penelitian yang digunakan untuk mengumpulkan data variabel penelitian adalah reliabel.

Setelah semua uji dilakukan, berikutnya dilakukan analisis statistik deskriptif. Dari jawaban-jawaban kuesioner kemudian disusun penilaian untuk setiap item berdasarkan persentase. Adapun hasil rekapitulasi analisis deskriptif terhadap variabel kinerja yaitu:

\section{Tabel 5 Analisis Statistik Deskriptif Variabel Kinerja}

\begin{tabular}{clcc}
\hline No & \multicolumn{1}{c}{ Dimensi } & Rata-Rata Skor & Persentase \\
\hline 1 & Kepemimpinan & 333 & $75.68 \%$ \\
2 & Perencanaan Strategis & 318.5 & $72.39 \%$ \\
3 & Fokus Pelanggan & 331.5 & $75.33 \%$ \\
4 & Pengukuran, Analisis Dan Manajemen & 338 & $76.59 \%$ \\
5 & Fokus Sumber Daya Manusia & 285 & $64.77 \%$ \\
6 & Manajemen Proses & 334.5 & $76.02 \%$ \\
7 & Hasil & 342.5 & $75.34 \%$ \\
\hline \multicolumn{2}{c}{ Rata-rata } & 326.14 & $73.73 \%$ \\
\hline
\end{tabular}

Sumber: Hasil Olahan Penulis, 2019

Berdasarkan hasil yang diperoleh di lapangan, maka diperoleh hasil pada dimensi hasil dengan rata-rata skor sebesar 342.5 dan dimensi terendah yaitu fokus sumber daya manusia dengan rata-rata skor sebesar 285. Hal ini menunjukan bahwa di PT. POS Indonsia, dimensi hasil merupakan dimensi yang paling berpengaruh terhadap kinerja perusahaan dengan persentase sebesar $75.34 \%$. Berbeda halnya dengan dimensi fokus sumber daya manusia yang hanya memiliki persentase sebesar $64.77 \%$. Tentunya kedua dimensi tersebut dan juga dimensi lainya tetap membutuhkan sebuah perbaikan maupun perubahan untuk meningkatkan kinerja perusahaan yang akan berdampak pada keunggulan bersaing yang dimiliki oleh PT Pos Indonesia.

Adapun hasil rekapitulasi analisis deskriptif variabel keunggulan bersaing yaitu:

Tabel 6 Analisis Statistik Deskriptif Variabel Keunggulan Bersaing

\begin{tabular}{clcc}
\hline No & Dimensi & Rata-Rata Skor & Persentase \\
\hline 1 & Cost Leadership & 341 & $77.5 \%$ \\
2 & Diferensiasi & 361 & $82.04 \%$ \\
3 & Fokus & 315 & $71.59 \%$ \\
\hline & Rata-Rata & 339 & $77.04 \%$ \\
\hline
\end{tabular}

Sumber: Hasil Olahan Penulis, 2019

Berdasarkan hasil yang diperoleh di lapangan maka diperoleh hasil skor tertinggi yaitu pada dimensi diferensiasi dengan rata-rata skor sebesar 361 dan dimensi terendah yaitu fokus dengan rata-rata skor sebesar 315 . Hal ini menunjukan bahwa di PT. Pos Indonsia dimensi diferensiasi merupakan dimensi penilaian keunggulan bersaing yang terbaik dibandingkan dengan dimensi lainya. Semua dimensi yang menjadi penilaian terhadap keunggulan bersaing 
yang dimiliki oleh PT Pos Indonesia tetap membutuhkan suatu perbaikan dengan tujuan untuk meningkatkan keunggulan bersaing yang dimiliki oleh PT Pos Indonesia.

Analisis berikutnya yaitu analisis regresi linear sederhana untuk mengetahui bagaimana pengaruh kinerja terhadap keunggulan bersaing. Berdasarkan pengolahan data, diperoleh hasil sebagai berikut:

Tabel 7 Output Koefisien Regresi

\begin{tabular}{|c|c|c|c|c|c|c|}
\hline & \multirow{2}{*}{ Model } & \multicolumn{2}{|c|}{$\begin{array}{l}\text { Unstandardized } \\
\text { Coefficients }\end{array}$} & \multirow{2}{*}{$\begin{array}{c}\begin{array}{c}\text { Standardized } \\
\text { Coefficients }\end{array} \\
\text { Beta }\end{array}$} & \multirow{2}{*}{$\mathbf{T}$} & \multirow{2}{*}{ Sig. } \\
\hline & & B & Std. Error & & & \\
\hline \multirow[t]{2}{*}{1} & (Constt) & 1.687 & .997 & & 1.693 & .094 \\
\hline & MBC fPE & .117 & .016 & .609 & 7.122 & .000 \\
\hline
\end{tabular}

Sumber: Hasil Olahan Penulis, 2019

Tabel tersebut memperlihatkan output koefisien regresi sehingga diperoleh persamaan $\mathrm{Y}=$ $\mathrm{a}+\mathrm{bX}$ adalah $\mathrm{Y}=1.687+0,117 \mathrm{X}$. Maka dapat disimpulkan bahwa kinerja perusahaan berpengaruh positif terhadap keunggulan bersaing di PT Pos Indonesia.

Untuk menguji hipotesis yang berbunyi "Terdapat pengaruh yang signifikan antara kinerja perusahaan terhadap keunggulan bersaing", maka dilakukan uji $\mathrm{F}$ simultan dengan kriteria:

Jika Fpenelitian > Ftabel maka $\mathrm{H} 0$ ditolak dan $\mathrm{H} 1$ diterima

Jika Fpenelitian < Ftabel maka H0 diterima dan $\mathrm{H} 1$ ditolak

Berdasarkan pengolahan data, diperoleh hasil sebagai berikut:

Tabel 8 Uji F Simultan

ANOVAa

\begin{tabular}{|c|c|c|c|c|c|c|}
\hline \multicolumn{2}{|c|}{ Model } & $\begin{array}{l}\text { Sum of } \\
\text { Squares }\end{array}$ & df & $\begin{array}{r}\text { Mean } \\
\text { Square }\end{array}$ & $\mathbf{F}$ & Sig. \\
\hline \multirow[t]{3}{*}{1} & Regression & 138.167 & 1 & 138.167 & 50.724 & $.000^{\mathrm{b}}$ \\
\hline & Residual & 234.256 & 86 & 2.724 & & \\
\hline & Total & 372.423 & 87 & & & \\
\hline
\end{tabular}

a. Dependent Variabel: Keunggulan Bersaing

b. Predictors: (Constant), MBCfPE

Berdasarkan Tabel tersebut diperoleh hasil nilai Fhitung 50,724 sedangkan Ftabel adalah 4,41. Apabila nilai Fhitung > Ftabel maka dapat disimpulkan Ho ditolak, artinya ada hubungan linier antara kinerja perusahaan dengan keunggulan bersaing.

Uji yang selanjutnya dilakukan yaitu Uji $\mathrm{T}$ atau uji partial untuk mengetahui seberapa besar pengaruh yang diberikan oleh tiap dimensi variabel kinerja terhadap keunggulan bersaing. Kriteria pengambilan keputusan untuk hipotesis yang diuji adalah :

1) Jika t hitung $<\mathrm{t}$ tabel berarti Ha ditolak dan $\mathrm{H}_{0}$ diterima

2) Jika t hitung $>\mathrm{t}$ tabel berarti Ha diterima dan $\mathrm{H}_{0}$ ditolak

3) Jika tingkat signifikansi $<0.05 \mathrm{Ha}$ diterima dan $\mathrm{H}_{0}$ ditolak

4) Jika t hitung < t tabel berarti Ha ditolak dan $\mathrm{H}_{0}$ diterima 
Volume 12, No. 1, April 2020, pp. 1-9

e-ISSN: 2502-5449

p-ISSN: 2085-2266

DOI : $10.30998 /$ sosioekons.v12i1.5672

Berdasarkan pengolahan data, ditemukan hasil sebagai berikut:

Tabel 9. Uji T

Coefficients ${ }^{a}$

\begin{tabular}{|c|c|c|c|c|c|}
\hline \multirow[b]{2}{*}{ Model } & \multicolumn{2}{|c|}{$\begin{array}{l}\text { Unstandardized } \\
\text { Coefficients }\end{array}$} & \multirow{2}{*}{$\begin{array}{r}\begin{array}{r}\text { Standardized } \\
\text { Coefficients }\end{array} \\
\text { Beta } \\
\end{array}$} & \multirow[b]{2}{*}{$\mathrm{t}$} & \multirow[b]{2}{*}{ Sig. } \\
\hline & B & Std. Error & & & \\
\hline (Constant) & 1.634 & 1.018 & & 1.605 & .112 \\
\hline KEPEMIMPINAN & .294 & .179 & .131 & 1.639 & .105 \\
\hline PERENCANAAN & & & & & \\
\hline STRATEGIS & .116 & .099 & .127 & 1.173 & .244 \\
\hline FOKUS PASAR & & & & & \\
\hline PELANNGAN & -.079 & .169 & -.058 & -.466 & .642 \\
\hline PENGUKURAN DAN & & & & & \\
\hline ANALISIS & -.197 & .131 & -.198 & -1.498 & .138 \\
\hline FOKUS SDM & .105 & .093 & .124 & 1.126 & .264 \\
\hline MANAJEMEN PROSES & .148 & .152 & .126 & .971 & .334 \\
\hline HASIL & .593 & .105 & .648 & 5.637 & .000 \\
\hline
\end{tabular}

a. Dependent Variabel: Keunggulan bersaing

Sumber: Hasil Olahan Penulis, 2019

Berdasarkan tabel tersebut dapat diketahui bahwa hanya dimensi hasil yang menunjukkan taraf signifikan $<0.05$ yaitu dengan 0.00 sedangkan yang lain berada di atas atau $>0.05$ begitu pun dengan $\mathrm{t}_{\text {Tabel}}$, maka dapat ditarik kesimpulan bahwa $\mathrm{H}_{\mathrm{a}}$ ditolak dan $\mathrm{H}_{0}$ diterima. Kesimpulan yang dapat ditarik dari hasil analisis tersebut yaitu indicator hasil merupakan iindikator yang berpengaruh di mana hasil tersebut diarahkan pada hasil mutu produk dan layanan serta kepuasan pelanggan di PT Pos Indonesia.

Nilai koefisien determinasi variabel kinerja terhadap keunggulan bersaing yaitu:

Tabel 10 Koefisien Determinasi

Model Summary

\begin{tabular}{ccrcr}
\hline Model & R & $\begin{array}{c}\text { R } \\
\text { Square }\end{array}$ & $\begin{array}{c}\text { Adjusted R } \\
\text { Square }\end{array}$ & $\begin{array}{c}\text { Std. Error of } \\
\text { the Estimate }\end{array}$ \\
\hline 1 & $.609^{\mathrm{a}}$ & .371 & .364 & 1.65042 \\
\hline
\end{tabular}

a. Predictors: (Constant), MBC fPE

Hasil penelitian memperlihatkan bahwa berdasarkan tabel tersebut dengan nilai koefisien determinasi $\mathrm{R} 2=0,371$, yang artinya menunjukkan hubungan yang positif antara Kinerja Perusahaan (X) terhadap Keunggulan Bersaing (Y) adalah 37,1 \%, yang artinya 37,1\% Keunggulan Bersaing disebabkan oleh Kinerja Perusahaan, dan 62,9 \% dipengaruhi oleh faktor lain.

Berdasarkan hasil penelitian diperoleh hasil 326. 14, maka kinerja PT. Pos Indonesia yaitu berada pada level early result dimana terlihat PT. Pos Indonesia mengendurnya kegiatan operasional dalam hal pengiriman, juga tidak dapat memberikan jawaban memuaskan terkait keluhan, namum hal tersebut diatasi dengan menyusun strategi perbaikan kinerja yang PT. Pos Indonesia lakukan dengan meningkatkan kualitas pelayanannya dengan cara bekerja sama dengan SiCepat dan Haistar, menawarkan produk baru antara lain ialah Q9 Sameday Service 
yang merupakan layanan pengiriman barang sameday service dalam kota (khusus Pulau Jawa) dan Ibukota Propinsi untuk kota-kota di luar Pulau Jawa, dengan time limit maksimal 9 jam. QCOMM atau Quick Commerce yaitu produk khusus bagi pebisnis online (ambil paket gratis atau pick up gratis, resi otomatis serta COD menggunakan pos giro mobile) dan yang terkahir adalah Pos Assurance yang merupakan perlindungan asuransi jiwa degan harga terjangkau Rp5.000 dan Rp10.000 untuk manfaat selama 30 hari. Tidak sampai disana karena masih berada pada level early result maka setelah strategi perbaikan dilakukan untuk mengetahui keberhasilan strategi dalam meningkatkan kinerja unggul maka perlu kembali diukur dengan metode yang sama yaitu menggunakan metode malcom balrige, hal ini sesuai dengan pendapat (Regi, Ambar dan Sugih, 2015: 85) yang menyatakan "setelah melakukan perbaikan maka perlu dilakukan pengukuran kembali dengan metode sejenis agar dapat dilihat peningkatan score kinerja organisasi)", hal ini ditujukan untuk melihat indikator yang masih kurang dalam peningkatan kinerja.

\section{SIMPULAN DAN SARAN}

\section{Simpulan}

Berdasarkan hasil penelitian dan analisa yang telah dilakukan mengenai implementasi pengukuran kinerja perusahaan dengan model Malcolm Baldrige for Performance Excellence pada PT Pos Indonesia, maka diperoleh mengenai kinerja perusahaan pada PT Pos Indonesia.

Berdasarkan hasil analisis deskriptif, kinerja perusahaan pada PT Pos Indonesia termasuk dalam kategori baik, diukur dengan indikator kepemimpinan, perencanaan strategis, fokus pelanggan, pengukuran, analisis dan manajemen, fokus sumber daya manusia, manajemen proses dan hasil. Indikator tertinggi yaitu manajemen proses dengan persentase $76,02 \%$ dan indikator terendah yaitu fokus sumber daya manusia dengan persentase $64,77 \%$. Sementara keunggulan bersaing pada PT Pos Indonesia juga termasuk dalam kategori baik, diukur dengan indikator cost leadership, diferensiasi dan fokus. Indikator tertinggi yaitu diferensiasi dengan persentase $82.04 \%$ dan indikator terendah yaitu fokus dengan persentase $71.59 \%$.

Dari penelitian in dapat diketahui bahwa terdapat pengaruh positif dan signifikan kinerja perusahaan terhadap keunggulan bersaing PT Pos Indonesia dengan pengaruh sebesar 37,1\% arinya memiliki pengaruh rendah, sedangkan sisanya yaitu $62,9 \%$ dipengaruhi oleh faktor lain.

\section{Saran}

Berdasarkan pengamatan penulis mengenai pengukuran kinerja perusahaan, PT Pos Indonesia hanya memperhatikan hasil dari kinerjanya, namun kurang memperhatikan proses dalam mencapai itu, maka diharapkan PT Pos Indonesia lebih memperhatikan proses yang dilakukan dalam mencapai hasil yang diharapkan agar lebih maksimal lagi.

\section{DAFTAR RUJUKAN}

Regi Mayani, Ambar Harsono, Sugih Arijanto. (2015). Pengukuran Performasi Berdasarkan MBCFPE Pada Kategori Proses Fokus Operasi Serta Kategori Hasi Item Produk dan Proses Di Yayasan X.

Katadata. (2018). website belanja online di indonesia dan ekspedisi yang digunakan.

Sugiyono. (2017). Statistika Untuk Penelitian.

Utami, P. Setyorini, R. (2014). Analisis Pengaruh Kriteria Lainnya Dalam Malcolm Baldrige Criteria for Performance Excellence (MBCFPE) Terhadap Kepemimpinan Pada PT Krakatau Steel (Persero), 1(3).

www.posindonesia.co.id. (2018). 